\title{
Correction to: Discrete analogues of continuous bivariate probability distributions
}

\author{
Alessandro Barbiero ${ }^{1}$ \\ (๑) Springer Science+Business Media, LLC, part of Springer Nature 2019

\section{Correction to: Annals of Operations Research https://doi.org/10.1007/s10479-019-03388-8}

This erratum is published as vendor overlooked corrections on Table 6 and deleted two references "Barbiero IWAP (2018b) and ANOR (2019)" in list and mistakenly changed the citation to "Barbiero (2019)" in line number 460 instead of deleting it.

The original article has been updated thus.

Publisher's Note Springer Nature remains neutral with regard to jurisdictional claims in published maps and institutional affiliations.

The original article can be found online at https://doi.org/10.1007/s10479-019-03388-8.

$凶$ Alessandro Barbiero alessandro.barbiero@unimi.it

1 Department of Economics, Management and Quantitative Methods, Università degli Studi di Milano, via Conservatorio 7, 20122 Milan, Italy 